\title{
Análise do impacto do impulso fiscal na taxa de juros para países selecionados com metas de inflação para o período de 1995 a 2013
}

\author{
Wagner Eduardo Schuster \\ Divanildo Triches ${ }^{* * *}$ \\ Luís Antônio Sleimann Bertussi"****
}

\begin{abstract}
Resumo
O presente trabalho tem como objetivo analisar o impacto causado pela Política Fiscal na taxa de juros em países com metas de inflação ao longo do período de 1995 a 2013. Mais diretamente, o impacto causado pelo impulso fiscal, uma variável criada para descrever os gastos discricionários do governo, ou seja, aqueles gastos que o governo tem a opção de fazê-los ou não, diferenciando-os dos gastos obrigatórios e/ou automáticos. Foi utilizado um modelo econométrico com dados em painel para avaliar o impacto causado pelo impulso fiscal na taxa de juros de 23 países. O resultado encontrado foi positivo, ou seja, um aumento nos gastos discricionários do governo gera um aumento na taxa de juros. Mais precisamente, um aumento em 1 ponto percentual no impulso fiscal acarreta em um aumento de 0,13 pontos percentuais na taxa de juros.
\end{abstract}

Palavras-chave: Análise em painel. Política fiscal. Taxa de juros.

* Graduado em Ciências Econômicas pela Universidade de Passo Fundo. E-mail: wagner.schuster92@ gmail.com

** Doutor em Economia pela Universidade Federal do Rio Grande do Sul. Pesquisador e professor no Programa de Pós-Graduação em Economia da Universidade do Vale do Rio dos Sinos, PPGE/Unisinos. E-mails: divanildo@pq.cnpq.br e divanildot@unisinos.br

*** Mestre em Economia pela Universidade do Vale do Rio dos Sinos (Unisinos). Professor da Universidade de Passo Fundo. E-mail: luisbertussi@upf.br

http://dx.doi.org/10.5335/rtee.v23i49.8252

Submissão: 29/03/2017. Aceite: 19/12/2017. 


\section{Introdução}

Atualmente, muitos países utilizam a Regra de Taylor para controle da inflação, ou seja, utilizam a política monetária para corrigir o aumento ou a diminuição do nível geral dos preços. Nos últimos anos vários estudos vêm evidenciando que existem outros fatores capazes de controlar a inflação, além da alteração da taxa de juros conforme proposto por Taylor (1993), sendo que, dentre esses fatores, destaca-se a Política Fiscal e seu impacto em tal taxa, o que apesar de ser um tema recente na literatura econômica, já existem vários estudos evidenciando tais relações de efeitos.

O impacto causado na taxa de juros pelos gastos do governo pode ser explicado pelo efeito deslocamento decorrente da política fiscal. Barro (1981) e Dornbusch e Fischer (1991) afirmam que a política fiscal impacta na demanda agregada, afetando o nível de produção e renda, essa alteração no nível de renda, por sua vez, impacta na demanda por moeda que acaba por impactar na taxa de juros para manter o equilíbrio. Barros (2012) afirma que o impacto causado pela política fiscal na taxa de juros ocorre devido ao fato de que o governo, ao aumentar seus gastos, gera uma pressão sobre o nível de preços, pois afeta a demanda agregada. Dessa forma, como os países que utilizam sistema de metas para inflação seguem uma regra do tipo Taylor, ocorre um aumento na taxa de juros de curto prazo para conter a inflação.

Existem na literatura várias categorias de modelos que foram utilizados para buscar explicar o impacto que a política fiscal pode ter na taxa de juros e muitos deles encontraram resultado positivo. Blinder e Solow (1972) utilizaram um modelo keynesiano com preços rígidos. Hebous (2010) fez um estudo teórico com um modelo de equilíbrio geral. Perotti (2004) analisou países da OCDE, utilizando um modelo VAR. Aisen e Hauner (2008) utilizaram um modelo em painel que incluía os países da OCDE e também alguns países emergentes na amostra. Ardagna, Caselli e Lane (2004) utilizaram um modelo em painel com dados dos países membros do OCDE. Ardagna (2004) utiliza um modelo em painel contendo dados dos países da OCDE em um período que compreende entre 1960 à 2002. Barros (2012) utilizou um modelo em painel não balanceado contendo dados anuais do período de 1990 à 2008 de diversos países selecionados. Moreira e Rocha (2011) analisaram também em um modelo em painel, dados de países emergentes no período entre $1996 \mathrm{e}$ 2008.

Em especial, pelo atual cenário econômico mundial e pelo papel da política fiscal como ferramenta de ação macroeconômica, este trabalho realiza um estudo sobre o impacto da política fiscal nas taxas de juros de um grupo de países 
selecionados que utilizam sistema de metas de inflação. O que, além de trazer um efeito fixo para o modelo, justifica-se na medida em que o impulso fiscal causa o aumento da taxa de juros para conter pressões inflacionárias, principalmente em países com sistema de metas para inflação, pois esses utilizam a Regra de Taylor.

O modelo em painel balanceado contou com dados anuais de 23 países para 0 período 1995 a 2013. Essa investigação permite evidenciar qual o impacto que alterações nos gastos discricionários do governo podem provocar nas taxas de juros. Foram incorporados apenas os gastos discricionários do governo, ou seja, aqueles gastos que o governo tem a opção de realizá-los. Para tanto criou-se uma variável chamada de impulso fiscal, a qual exclui os gastos automáticos do governo.

Dessa forma, o objetivo geral deste trabalho é investigar a hipótese de que a política fiscal tem efeito ou não na taxa de juros para os países selecionados. Como objetivos específicos o trabalho traz os seguintes: i) apresentar uma revisão teórica sobre estudos que analisaram o impacto da política fiscal na taxa de juros; ii) estimar um modelo de dados em painel para verificar se existe mesmo impacto da Política Fiscal nas taxas de juros nos países selecionados e; iii) fazer uma análise dos dados obtidos na estimação, comparando-os com outros resultados encontrados em estudos semelhantes.

A principal motivação desse estudo está baseada na crise recente dos países europeus por apresentarem déficits fiscais elevados. Os governos que mantiveram por vários períodos gastos públicos excessivos com benesses sociais acabaram por entrar em colapso como mostra Heredia (2014). Os países como Portugal, Itália, Irlanda, Grécia, Espanha, entre outros, tiveram que passar por fortes políticas restritivas, visando diminuírem fortemente os seus gastos públicos. A situação da economia brasileira tende a ter uma trajetória bastante semelhante. No entanto, algumas medidas estão sendo tomadas, como cortes no orçamento, que acabaram tendo fortes implicações sociais. Nesse contexto, destaca-se o papel da política fiscal e a possibilidade de avaliar o seu impacto nas taxas de juros.

O trabalho está dividido em três seções, além da introdução. Na seção dois, encontra-se a revisão dos estudos empíricos sobre os efeitos da politica fiscal na taxa de juros. Na terceira seção, são tratados aspectos metodológicos de estimação e definições de variáveis. A descrição e a análise dos resultados estão na quarta seção e na última, apresentam-se as conclusões. 


\section{Efeitos da política fiscal na taxa de juros}

O impacto da política fiscal na taxa de juros é um tema que começou a ser sistematicamente tratado em um período recente, tendo em vista a prioridade dada à política monetária nessa área. Porém, já existe uma literatura relativamente consistente que trata desse tema. Sims (2003), Favero (2004) e Acosta, Colom e Hernández (2012), por exemplo, defendem que deve existir um superávit primário, o qual deve ser mantido em um nível tal que a proporção da dívida em relação ao produto seja mantida constante. Segundo os autores, choques externos podem levar a uma situação de equilíbrio indesejável e nesse cenário a política monetária tornar-se-ia sem efeito ou, ainda pior, poderia ter efeitos contrários. Desta forma, Sims (2003), Favero (2004) e Romer e Romer (2007) defendem que a austeridade fiscal deve fazer parte de qualquer sistema de metas de inflação, para que esse possa ser efetivo.

Sargent e Wallace (1981) e Baxter (1993) afirmaram existir uma relação entre a política monetária e a política fiscal. Essa relação pode se dar de duas formas distintas, ou seja, quando a política fiscal é dominante, num período de déficits primários, a autoridade monetária tem que agir para poder garantir a solvência do governo. Por outro viés, quando a política monetária é a dominante, a taxa de juros no curto prazo é determinada pela autoridade monetária e a política fiscal apenas se ajusta para equilibrar o orçamento intertemporal do governo. Dornbusch e Fischer (1991) afirmam que a política fiscal impacta na demanda agregada, afetando o nível de produção e renda. Essa alteração no nível de renda, por sua vez, tem efeito na demanda por moeda que acaba influenciando a taxa de juros para manter o equilíbrio. Esse efeito é conhecido como deslocamento.

Outra explicação do efeito da política fiscal na taxa de juros se dá devido à pressão inflacionária causada pelo aumento na demanda agregada ocasionada pelo incremento dos gastos do governo. Barros (2012) afirma que o impacto causado pela política fiscal na taxa de juros ocorre devido ao fato de que o governo ao aumentar seus gastos gera uma pressão sobre o nível de preços por afetar a demanda agregada.

Barro e Redlick (2009), baseado em Evans (1985), empregaram como variável fiscal os gastos relacionados à defesa durante o período de guerra e mostraram que tais gastos não podem ser relacionados ao ciclo econômico. Ainda, Blanchard e Perotti (1999) utilizaram um modelo VAR para isolar o impacto do gasto fiscal exógeno. Alesina e Ardagna (1998) também buscaram separar os efeitos causados por aqueles gastos que foram considerados como gasto cíclico do governo, ou gasto 
automático. Já Gemmell, Kneller e Sanz (2011) utilizaram uma metodologia para separar os gastos do governo em produtivos e não produtivo para avaliar os impactos como cada um dos tipos de gastos provocam crescimento de longo prazo das economias. Barros (2012) empregou uma metodologia semelhante para estimar esse impacto nas taxas de juros. Para isso, definiu uma variável chamada impulso fiscal para separar os gastos discricionários do governo.

O modelo de equilíbrio geral foi empregado por Hebous (2010) e encontrou uma relação positiva entre a política fiscal e as taxas de juros de curto prazo. Perotti (2004) também teve como resultado de que choques de gastos fiscais produzem efeitos na taxa de juros de curto prazo para grande parte dos países da OCDE (Organização para Cooperação e Desenvolvimento Econômico). Aisen e Hauner (2008) utilizaram um modelo em painel também para países da OCDE (Alemanha, Austrália, Canadá, Estados Unidos e Reino Unido) e de alguns países de mercados emergentes. Os resultados mais robustos foram encontrados justamente nos países emergentes, ou seja, um aumento de $1 \%$ no déficit fiscal tende a gerar um aumento de aproximadamente 26 pontos-base na taxa de juros de curto prazo. Engen e Hubbard (2005), por meio de modelo VAR, mostraram ainda que um impacto positivo do superávit primário provoca mudança na mesma direção na taxa de juros de longo prazo e a esse fato se daria pela redução na poupança agregada da economia. Essa conclusão foi corroborada pelo estudo anterior de Ardagna et al. (2004), porém usaram um modelo em painel para os países da OCDE ao longo de 1960 a 2002. O período considerado apresentou grande flutuações nos superávits fiscais primários em que as políticas anticíclicas e os estabilizadores automáticos não são capazes de produzirem efeitos significativos no resultado final. Já Gale e Orszag (2004) indicaram para economia dos Estados Unidos que um aumento em 1\% no déficit primário em relação o produto gera um aumento de 40 a 70 pontos base na taxa de juros de longo prazo.

A relação entre as projeções de déficits e dívidas no mercado futuro dos juros também para os Estados Unidos foi analisada por Laubach (2009). O autor enfatiza a necessidade de isolar alguns fatores que incidem sobre a dívida pública. Portanto foram isolados os efeitos fiscais, as influências relacionadas com o ciclo de negócios e da política monetária. O resultado encontrado foi de que existe uma relação entre os déficits e a taxa de juros. Nesse caso, uma elevação de $1 \%$ no déficit projetado em relação ao produto geraria um aumento de, aproximadamente, 25 pontos-base na taxa de juros de longo prazo.

Um modelo em painel não balanceado com informações anuais do período de 1990 a 2008 foi empregado por Barros (2012) para um conjunto países como 
Austrália, Bélgica, Bulgária, Canadá, Hong Kong, Macau, República Tcheca, Dinamarca, Egito, Estônia, Finlândia, França, Alemanha, Grécia, Hungria, Islândia, Irlanda, Israel, Itália, Japão, Cazaquistão, Letônia, Lituânia, Ilhas Maurício, Moldávia, Noruega, Polônia, Romênia, Rússia, Cingapura, África do Sul, Espanha, Suécia, Suíça, Ucrânia, Reino Unido e Estados Unidos. O resultado mostrou que política fiscal discricionária produz um impacto positivo e significativo na taxa de juros de curto prazo e na taxa de juros de longo prazo. Assim, para um aumento de um ponto percentual na variável denominada impulso fiscal, que representa 0 gasto fiscal discricionário, gera um aumento entre 10,9 e 12,7 pontos-base na taxa de juros de curto prazo, podendo chegar entre 52,0 a 110,0 pontos-base na de longo prazo. Moreira e Rocha (2011) analisaram também em um modelo em painel, ao longo do período de 1996 e 2008, para o conjunto de países emergentes como, África do Sul, Argentina, Brasil, Bulgária, Chile, China, Colômbia, Equador, Filipinas, Hungria, Indonésia, Malásia, México, Peru, Polônia, Rússia, Turquia e Venezuela. A seleção dessa amostra baseou-se em diversos aspectos como: sistema de metas de inflação, taxa de poupança, nível de reservas, regime cambial e político. Os resultados mostraram uma política fiscal austera tem o papel de reduzir a taxa de juros doméstica desses países e concluíram ainda que um aumento de $1 \%$ no superávit primário reduz entre 50 e 100 pontos-base os juros domésticos.

\section{Procedimento metodológico e definição de variáveis}

O painel balanceado, usado para o estudo, conta com informações anuais do período de 1995 a 2013 e contendo uma amostra 23 países que adotaram sistema de metas para inflação conforme Tabela 1 do Apêndice. Um painel é dito balanceado se cada unidade de corte transversal tem o mesmo número de observações como discutem Gujarati e Porter (2011). A escolha dos países com sistema de metas para inflação se deu em virtude do efeito fixo e pelo fato de que o impulso fiscal causa efeito na taxa de juros. Esse efeito fixo ocorre devido ao aumento da taxa de juros para conter pressões inflacionárias e com a finalidade de manter a taxa de inflação dentro da meta previamente estabelecida.

Dessa forma a hipótese a ser testada pelo modelo é a de que a política fiscal expressa por meio da variação dos gastos discricionários do governo - causa impacto na taxa de juros. Para tanto e seguindo a literatura, é utilizada uma variável de impulso fiscal. Assim para Baltagi (1995), os modelos em painel apresentam várias 
vantagens em relação a modelos de corte transversal ou de séries temporais. Uma delas é que, ao combinar dados temporais com dados em corte transversal, o modelo apresenta resultados mais eficientes, pois contem dados mais informativos e com maior variabilidade, apresentando menor colinearidade entre as variáveis e mais graus de liberdade. Outra vantagem é que dados em painel tem uma maior capacidade para medir os efeitos ao comparados com dados de corte ou série temporal, pois ao se trabalhar com painel obtemos uma quantidade muito maior de dados. Gujarati e Porter (2011) também defendem o uso de modelos em painel. Este estudo, por sua vez, segue o modelo proposto por Barros (2012), conforme a equação (1).

$$
j u r_{i t}=\beta_{0}+\beta_{1} j u r_{i-1}+\beta_{2} \hat{C}_{i}+\beta_{3} \hat{G}_{i}+\beta_{4} H_{i}+\beta_{5} \pi_{i}+\varepsilon_{i}
$$

em que jur é a taxa de juros, que também está incluída nos regressores, porém defasada em um período (t-1). Para Barros (2012), a variável defasada foi incluída no modelo para representar como a autoridade monetária suaviza os ajustes nas taxas de juros para controlar a inflação, ou seja, esse ajuste não ocorre de forma automática. $\mathrm{O}$ efeito dessa suavização no ajuste é representado portanto por $\beta_{1} \mathrm{e}$, dessa forma, quanto maior for $\beta_{1}$ maior será a inércia da taxa de juros.

A variável Ĉ representa consumo das famílias como proporção ao PIB de cada país. Ĝ representa o impulso fiscal e foi criada utilizando dados referentes ao gasto do governo em relação ao PIB como está descrita na próxima seção. Essa variável tem o intuito de separar os gastos discricionários do governo daqueles gastos considerados automáticos, que representados pelos chamados estabilizadores automáticos. A variável $\mathrm{H}$, representa o hiato do produto, obtida de acordo Taylor (1993), ou seja, por meio da subtração do PIB corrente pela sua tendência e dividindo o resultado pelo próprio PIB corrente. $\pi$ representa a taxa de inflação, medida pelos preços ao consumidor de todos os produtos em percentual de variação referente ao período anterior.

A previsão é de que o modelo se ajuste bem quanto aos testes aplicados e apresente resultados significativos. Espera-se encontrar relação em todas as variáveis explicativas. O resultado esperado é de que todos os sinais sejam positivos, ou seja, todas as variáveis independentes causem um impacto de mesmo sentido na variável endógena, ou seja, um aumento em uma das variáveis deve causar também um aumento na taxa de juros. Apesar de se esperar um sinal positivo para todas as variáveis, o centro da atenção neste estudo é a variável impulso fiscal. Espera-se encontrar significância e sinal positivo para o coeficiente uma vez que se entende que o aumento nos gastos discricionários do governo tem efeito apenas na demanda 
agregada e, dessa forma, o aumento no impulso fiscal eleva a renda disponível das famílias, porém não aumenta a produtividade das empresas, levando a uma pressão inflacionária, controlada pelo aumento nas taxas de juros.

O modelo pode ser utilizado como política de governo, uma vez que pode causar impacto na regra de Taylor, afetando a taxa de juros. Dessa forma, o modelo propõe que deva existir uma combinação entre as políticas monetárias e fiscais, e não apenas controle via alteração das taxas de juros. Conforme proposto, uma redução no impulso fiscal via política fiscal pode gerar redução na taxa de juros. ${ }^{1}$

As variáveis para as taxas de juros e taxa de inflação foram extraídas do International Finance Statistics (IFS) do FMI. Já para o consumo e o para o PIB, foram utilizadas as informações do World Development Indicators (WDI) do Banco Mundial, com preços constantes em moeda dos Estados Unidos de 2005. A variável impulso fiscal foi construída seguindo a metodologia de Barros (2012), com ajustamento na série de gastos do governo. Esse procedimento permite separar os gastos discricionários daqueles gastos em virtude de ajustes automáticos. $\mathrm{O}$ impulso fiscal representa, portanto, a variação nos gastos discricionários do governo em relação ao período anterior. Primeiramente, obteve-se a série de gastos do governo em porcentagem do PIB e após, segregou-se os gastos do governo em gastos discricionários e não-discricionários. Esse tratamento metodológico foi, inicialmente, proposto por Alesina e Ardagna (1998).

Assim, os gastos não-discricionários podem ser relacionados com o nível de desemprego, por serem considerados estabilizadores automáticos, uma vez que eles ocorrem principalmente quando há alterações nesse nível de desemprego. Portanto, as informações estatísticas para a taxa de desemprego foram extraídas a partir da base de dados do International Finance Statistics do FMI. A variável impulso fiscal é construída por meio da estimação da equação (2)

$$
\operatorname{Exp}_{t}=\alpha+\beta_{1} T+\beta_{2} U_{t}+e_{t}
$$

em que $\operatorname{Exp}_{t}$ é os gastos do governo, $T$ a tendência, Exp, a taxa de desemprego e $e_{t}$ é erro aleatório. Após a estimativa de $E x p_{1}$, gera-se o gasto ciclicamente ajustado, $\operatorname{Exp}_{t}^{c a}$ conforme equação (3)

$$
\operatorname{Exp}_{t}^{a}=\hat{\alpha}+\hat{\beta}_{1} T+\hat{\beta}_{2} U_{t-1}+\hat{e}_{t}
$$

Para a obtenção da variável que representa o impulso fiscal, é necessário apenas subtrair o valor estimado da equação (3) daquele estimado da equação (2). O hiato do produto foi calculado por meio do filtro de Hodrick-Prescott, com frequência 
de 6,25, que é o valor recomendado para dados anuais como abordam Ravn e Uhlig (2002). Esse procedimento é idêntico àquele sugerido por Barro (2012) ou o usado por Taylor (1993).

\section{Descrição e análise dos resultados}

A média e o desvio padrão da inflação, taxa de juros, gastos do governo e impulso fiscal, obtido nos dados dos 23 países ao longo do período de 1995 a 2013 estão reportados na Figura 1. A linha contínua no centro indica a taxa média dos países da amostra, enquanto as linhas pontilhadas representam um desvio padrão para cima e um desvio padrão para baixo. Observa-se nos gráficos que houve uma ligeira queda nos gastos do governo e na taxa de juros, principalmente no período anterior à crise de 2008. O período foi de relativa estabilização nas variáveis inflação e impulso fiscal.

Figura 1 - Média e desvio padrão das variáveis: inflação, gastos do governo, taxa de juros e impulso fiscal

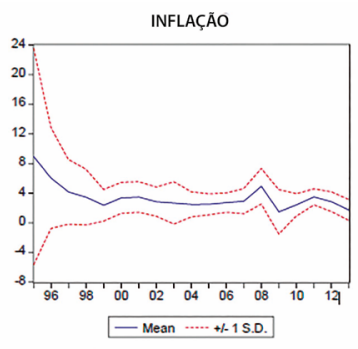

(a) Média e desvio padrão da inflação (em \%)

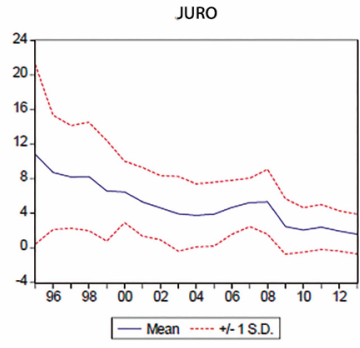

(c) Média e désvio padrão da taxa de juros

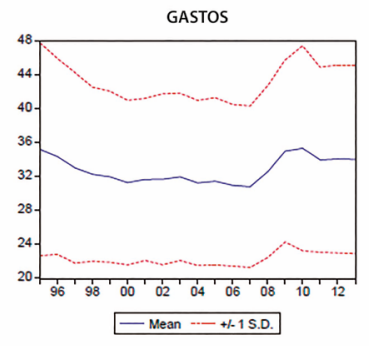

(b) Média e desvio padrão dos gastos do governo (em porcentagem do PIB)

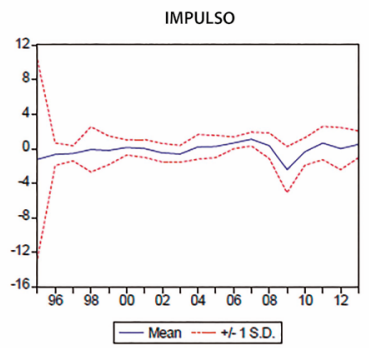

(d) Média e desvio padrão do impulso físcal

Fonte: WDI do Banco Mundial e no IFS do Fundo Monetário Internacional. 
O gráfico $a$ da Figura 1 apresenta a média da inflação dos 23 países. Destaca-se que a série apresenta certa estabilidade da inflação no período, principalmente no período entre 2000 e 2007. Esse fato pode ser explicado na medida em que todos os países utilizam sistema de metas de inflação. A queda entre o começo da série, em 1995, até o ano 2000 pode ter ocorrido devido ao fato de muitos países terem começado a utilizar o sistema de metas para inflação a partir do final da década de 1990 e início dos anos 2000, como é o caso de: Brasil (1999), Islândia (2001), Coréia (1998), República Tcheca (1998), Hungria (2001), entre outros. A partir de 2008, nota-se um aumento na inflação que posteriormente acaba voltando a cair.

No gráfico b da Figura 1 estão os gastos dos governos dos países em relação ao seu PIB que mostra um ligeiro declínio desses desde o começo da série até o ano de 2008, quando houve um aumento devido a políticas fiscais expansionistas com intuito de obter resultados anticíclicos no período pós-crise. Posteriormente, observa-se uma estabilização dos gastos.

O gráfico $\mathrm{C}$ da Figura 1 apresenta a média e o desvio padrão da taxa de juros dos 23 países. Nota-se que a taxa de juro está em declínio, em acordo com o declínio dos gastos do governo, salvo no período da crise de 2008 quando a taxa de juro acabou elevando-se por um tempo e, após esse período, retornaram sua trajetória de queda.

No gráfico d da Figura 1 está representada a média e os desvios padrões para a variável impulso fiscal. Nota-se que a série é bastante estável, só tendo um período de baixa que ocorreu no período entre 2009 e 2010, justamente após a crise internacional, quando a maioria dos países se viu obrigado a reduzir seus gastos públicos.

Na Tabela 1, estão as médias das variáveis utilizadas no modelo para cada um dos 23 países. Constam na tabela as variáveis: juro, consumo em porcentagem do PIB, gastos do governo em porcentagem do PIB, inflação e desemprego. De modo geral, as médias registradas para os 23 países estão relativamente próximas, porém nota-se que em alguns casos registraram-se valores muito divergentes, como é o caso da inflação no Brasil. Quanto ao consumo, em Cingapura temos o menor valor de média da série, sendo que apenas $37,63 \%$ do PIB é consumo das famílias, muito diferente da Grécia, onde, em média, o consumo representa 70,27\% do PIB. Já os gastos do governo representaram no período apenas 14,27\% do PIB em Cingapura enquanto na França chegaram a 46,57\%. No que se refere à inflação, a maior média foi registrada no Brasil, com 9,94\% no período e a menor na Suécia, com 1,25\%. Por fim, o desemprego obteve valor médio de 2,13\% em Cingapura, enquanto na Espanha chegou a incríveis $15,09 \%$ no período. 
É notório que países como Cingapura, que apresentou o menor desemprego em todos os anos da série e também obteve a menor média de consumo e gastos do governo em relação ao PIB, estão muito distantes de países como o Brasil, que teve a maior média de inflação e taxa de juros no período. Porém, vale lembrar que em uma amostra com 23 países, essas discrepâncias são atenuadas, tendo em vista que, na média geral, os países apresentaram valores bastante próximos.

Tabela 1 - Média das variáveis analisadas por país (\%)

\begin{tabular}{r|l|r|r|r|r|r}
\cline { 2 - 6 } & País & Juros & $\begin{array}{c}\text { Consumo/ } \\
\text { PIB }\end{array}$ & $\begin{array}{c}\text { Gastos/ } \\
\text { PIB }\end{array}$ & Inflação & Desemprego \\
\hline 1 & Brasil & 18.96 & 63.19 & 24.48 & 9.94 & 8.45 \\
3 & Austrália & 5.19 & 57.60 & 25.40 & 2.73 & 6.07 \\
4 & Bélgica & 2.47 & 52.45 & 43.86 & 2.00 & 11.15 \\
5 & Canadá & 3.05 & 55.48 & 18.82 & 1.91 & 7.63 \\
6 & República Tcheca & 5.08 & 49.66 & 33.39 & 3.97 & 8.14 \\
7 & Einamarca & 3.03 & 48.47 & 37.82 & 2.11 & 5.53 \\
8 & Fstônia & 4.29 & 53.76 & 30.37 & 6.93 & 10.19 \\
9 & Franlândia & 2.84 & 51.75 & 38.69 & 1.68 & 10.44 \\
10 & Alemanha & 2.65 & 56.87 & 46.57 & 1.57 & 9.07 \\
11 & Grécia & 2.54 & 58.33 & 31.42 & 1.54 & 8.62 \\
12 & Islândia & 5.02 & 70.27 & 46.11 & 3.70 & 12.24 \\
13 & Irlanda & 8.82 & 56.13 & 33.11 & 4.81 & 3.96 \\
14 & Israel & 2.93 & 46.27 & 37.12 & 2.38 & 9.13 \\
15 & Itália & 6.77 & 55.25 & 44.33 & 3.70 & 7.99 \\
16 & Cingapura & 3.69 & 59.18 & 41.33 & 2.43 & 9.24 \\
17 & Espanha & 1.91 & 37.63 & 14.27 & 1.82 & 2.13 \\
18 & Suécia & 3.57 & 57.29 & 30.17 & 2.78 & 15.09 \\
19 & Reino Unido & 3.12 & 48.62 & 35.39 & 1.25 & 6.58 \\
20 & Estados Unidos & 3.90 & 63.44 & 39.94 & 2.18 & 6.42 \\
21 & Coréia do Sul & 2.77 & 66.48 & 21.28 & 2.41 & 6.00 \\
23 & Peru & 5.78 & 51.22 & 17.15 & 3.36 & 3.65 \\
\hline
\end{tabular}

Fonte: WDI do Banco Mundial e no IFS do Fundo Monetário Internacional. 
Na Tabela 2, encontram-se a média, o desvio padrão e os valores de máximo e mínimo das variáveis taxa de juros, consumo (em \% do PIB), gastos do governo (em $\%$ do PIB), o impulso fiscal, o hiato do PIB e a inflação. Esses valores representam a média, o desvio padrão e os valores de máximo e mínimo de todo o período da amostra, de 1995 a 2013, de todos os 23 países.

Observa-se tanto pela Tabela 1 como pela Tabela 2 que o período de análise para os 23 países apresenta uma relativa estabilidade para essas variáveis. Todavia, ao analisar os valores de máximo e de mínimo de algumas variáveis, encontram-se alguns valores bastante distantes da média, porém, são apenas alguns pontos em alguns períodos específicos, o que pode ser comprovado pelo desvio padrão baixo.

Tabela 2 - Estatística descritiva por variável

\begin{tabular}{l|c|c|c|c}
\hline \multicolumn{1}{c|}{ Variável } & Média & Desvio padrão & Mínimo & Máximo \\
\hline Taxa de Juros & 5.06 & 5.22 & -0.02 & 49.93 \\
Consumo & 55.68 & 7.67 & 31.69 & 78.34 \\
Gastos & 32.77 & 10.44 & 11.92 & 62.15 \\
Impulso fiscal & -0.14 & 3.05 & -27.63 & 26.37 \\
Hiato PIB & -0.47 & 1.77 & -15.88 & 0.91 \\
Inflação & 3.41 & 4.51 & -4.48 & 66.01 \\
\hline
\end{tabular}

Fonte: WDI do Banco Mundial e no IFS do Fundo Monetário Internacional.

O resultado da estimação do modelo econométrico encontra-se reportado na Tabela 3. Nota-se que os valores para R-quadrado e R-quadrado ajustado foram de 0.846 e R-quadrado ajustado de 0.845 , o que demostram que as variáveis independentes explicam mais do que $80 \%$ da variável dependente, representada pela taxa de juros. O teste de correlação serial dos resíduos de Durbin-Watson foi de de 1,711 o qual indica ausência de autocorrelação.

Salienta-se ainda que a taxa de juros defasada em um período tem impacto na taxa de juros presente. Tal variável mostrou-se significante inclusive a um nível de $1 \%$ de significância. Esse fato permite afirmar que um aumento de um ponto percentual na taxa de juros do ano anterior gera um impacto de 70,0 pontos base na taxa de juros presente, o que pode explicar que existe um ajuste na taxa de juros de forma amenizada, ou seja, a autoridade monetária não faz o ajuste na taxa de juros de forma automática. Segundo Barros (2012) a variável taxa de juros defasada representa a inércia da taxa de juros e o valor de seu coeficiente demonstra o nível de suavização que ocorre no ajuste da taxa de juros. 
O consumo das famílias também causa impacto na taxa de juros. Como seu coeficiente foi significativo a um nível de $5 \%$, uma alteração de um ponto percentual na variável consumo em relação ao PIB causa um efeito de $0,02 \%$ na taxa de juros. Esse resultado está dentro do esperado, tendo em vista que um aumento no consumo das famílias pode gerar pressões inflacionárias, que são inibidas via aumento nas taxas de juros. Blinder e Solow (1973) afirmaram que um aumento na demanda agregada acarreta em aumento nas taxas de juros, com a finalidade de reestabelecer o equilíbrio na economia. Barro (1981) também afirma que um aumento no consumo agregado gera uma pressão inflacionária, que, por sua vez, é diminuída via aumento na taxa de juros.

Tabela 3 - Resultado da estimação do modelo econométrico

\begin{tabular}{|c|c|}
\hline Variável & Coeficiente \\
\hline $\mathrm{C}$ & $\begin{array}{c}-1.174224^{* * *} \\
(0.666)\end{array}$ \\
\hline Juro(-1) & $\begin{array}{l}0.7041^{*} \\
(0.0227)\end{array}$ \\
\hline Consumo/PIB & $\begin{array}{l}0.0265^{\star *} \\
(0.0120)\end{array}$ \\
\hline Impulso & $\begin{array}{l}0.1198^{* *} \\
(0.0539)\end{array}$ \\
\hline Inflação & $\begin{array}{l}0.2414^{*} \\
(0.0401)\end{array}$ \\
\hline Hiato do Produto & $\begin{array}{c}0.9225^{* * *} \\
(0.4955)\end{array}$ \\
\hline Variável dependente & Juros \\
\hline Método & Painel/ Mínimos quadrados \\
\hline Amostra & $1995-2013$ \\
\hline Cross-sections incluída & 23 \\
\hline Total de observações no painel balanceado & 414 \\
\hline R-quadrado & 0.8469 \\
\hline R-quadrado ajustado & 0.8450 \\
\hline Durbin-Watson & 1.7115 \\
\hline
\end{tabular}

Notas: Erro padrão entre parênteses. Significância: *1\%, **5\%, ${ }^{* * *} 10 \%$.

Outra variável que causa impacto na taxa de juros é a inflação que foi considerada significativa a um nível de $1 \%$. O impacto causado na taxa de juros pela variação dos níveis de preços é de 0,24 pontos percentuais, para cada alteração de $1 \%$ na inflação. Este resultado pode ser explicado pelo fato de todos os países utilizados no modelo adotarem sistema de metas para inflação. A variação no hiato do PIB também causa impacto na taxa de juros, isto é, um aumento de um ponto 
percentual no hiato do PIB gera um impacto de $0,92 \%$ na taxa de juros. Assim, o resultado encontrado justifica-se na medida em que a economia ao se aproximar do pleno emprego acaba gerando pressão inflacionária, a qual também é inibida por meio da elevação nas taxas de juros.

O resultado econométrico para a variável impulso fiscal foi condizente com a expectativa, pois a variável apresentou um parâmetro positivo e significativo a 5\%, o que mostra que uma variação no impulso fiscal irá gerar um efeito no mesmo sentido para a taxa de juros ou uma elasticidade impulso fiscal em relação à taxa de juros de 0,1199. Essa conclusão implica que o aumento dos gastos discricionários pelo governo, gera uma elevação da renda disponível por parte das famílias, uma vez, que o custo das empresas não é afetado. Tal aumento do poder de compra provoca uma elevação na demanda agregada com consequentes pressões inflacionárias, tornando-se necessário maiores taxas de juros para reestabelecer o equilíbrio como já defendia Blinder e Solow (1972). Explicação semelhante também é encontrada por Barros (2012), ou seja, o governo ao aumentar seus gastos temporários acaba aumentando a renda disponível provocando um aumento no consumo agregado, que eleva a um crescimento no nível de preços. Contudo, como os países seguem um sistema de metas para inflação do tipo de uma regra do tipo Taylor, faz-se necessário uma elevação na taxa de juros de curto prazo para conter a pressão inflacionária.

Por fim, o resultado encontrado para a variável impulso fiscal é suportado pelos estudos empíricos existentes na literatura. Laubach (2009) e Gale e Orszag (2004), por exemplo, indicaram um resultado entre $0,25 \%$ a $0,70 \%$ para o mercado norte americano. Perotti (2004), para os países da OCDE, encontrou um valor entre $0,38 \%$ e $1,41 \%$ dependendo do país. Aisen e Hauner (2008) estenderam a análise para além dos países da OECD, incluindo economias emergentes e encontraram um resultado de $0,26 \%$ no curto prazo podendo chegar a $0,77 \%$ no longo prazo. Moreira e Rocha (2010) também para economias emergentes encontraram um valor entre $0,50 \%$ e $1 \%$.

\section{Conclusões}

O emprego do modelo econométrico com dados em painel para 23 países selecionados com meta de inflação permitiu concluir que o impulso fiscal - variável que representa os gastos discricionários do governo - tem efeito sobre a taxa de juros. De forma mais precisa, um aumento de $1 \%$ no impulso fiscal gera um aumento de $0,12 \%$ na taxa de juros e vice-versa. Foi concluído também que todos os coeficientes 
encontrados são significativos a um nível de 10\% de significância. Tais coeficientes explicam $84 \%$ da variável dependente, sendo que o modelo não apresentou autocorrelação nos resíduos.

Especificamente, a taxa de juros defasada em um período tem impacto na própria variável no período presente o que revela a existência de uma suavização no ajuste na taxa de juros. O consumo das famílias também tem efeito direto sobre a taxa de juros. Tal resultado é esperado e sustentado pela literatura, pois um aumento no consumo das famílias pode gerar pressões inflacionárias, se a elevação da oferta agregadas não ocorrer na mesma velocidade. Essas pressões inflacionárias são combatidas via aumento nas taxas de juros com finalidade de manter a taxa de inflação dentro da meta estabelecida.

A taxa de inflação tem se mostrado relevante na determinação da taxa de juros, em particular, em países que adotaram o sistema de metas de inflação. Esse resultado também é observado no que diz respeito à variação no hiato do produto. Esse caso pode estar relacionado ao fato de que quando a economia se aproximar do pleno emprego, tensões inflacionárias adicionais são geradas e aliviadas por meio da elevação nas taxas de juros.

No que tange ao impulso fiscal, os resultados indicam que o parâmetro estimado foi condizente com o esperado - 0,1199. Isso mostra que uma elevação nos gastos discricionários do governo gera um incremento na renda disponível da sociedade. Novamente, tal efeito pode dar origem a pressões inflacionárias via crescimento na demanda agregada. Por fim, os resultados permitem concluir que o papel da política fiscal também é crucial para o controle das taxas de juros. Essa eficácia aumenta quando as autoridades governamentais utilizam uma combinação entre política fiscal e monetária. 


\title{
Analysis of the impact of tax policy on the interest rate for selected countries with inflation targets for the period from 1995 to 2013
}

\begin{abstract}
The objective of this document is to analyze the possible impact, caused by the Fiscal's Policy, in the interest rate. More directly, the impact caused by the fiscal effect, a variable created to describe the discretionary expenses of the government, in other words, the expenses that the government has the option of doing the or not, which are different from the obligatory expenses and/or automatic. An econometric model with panel data was used to find which is the impact caused by the fiscal effect in the interest rate of 23 countries between 1995 to 2013 . The result found was positive, in other words, an increase in the discrete expenses of the government generates an increase in the interest rates. More concretely, an increase of 1 percent in the fiscal effect, which entails on an increase of the 0,13 perceptual points in the interest rate.
\end{abstract}

Keywords: Fiscal policy, interest rate, panel data analysis

\section{Análisis del impacto de la política fiscal en la tasa de interés para los países seleccionados con metas de inflación para el periodo de 1995 a 2013}

\section{Resumen}

Este estudio tiene como objetivo analizar el impacto de la política fiscal sobre las tasas de interés en los países con metas de inflación durante el período de 1995 a 2013. De forma más directa, medir el impacto de los estímulos fiscales, una variable creada para describir el gasto discrecional del gobierno, es decir, aquellos gastos que el gobierno tiene la opción de hacer o no, diferenciándolos de aquellos obligatorios y/o automáticos. Se utilizó un modelo econométrico con datos de panel para evaluar el impacto del estímulo fiscal en la tasa de interés de 23 países entre 1995 y 2013. El resultado fue positivo, o sea, un aumento del gasto público discrecional genera un aumento de la tasa de interés. Más concretamente, un aumento de 1 punto porcentual en el estímulo fiscal provoca un incremento de 0,13 puntos porcentuales en las tasas de interés.

Palabras clave: Política fiscal, tasa de interés, análisis de datos de panel

JEL: C33; E47; E62 


\section{Nota}

1 Para a estimação do modelo utilizamos o software Eviews

\section{Referências}

ACOSTA, Edgar J. S.; COLOM, Jordi B.; HERNÁNDEZ, Josefa C. F. Los PIIGS en tiempos de crisis de deuda soberana: la pertinencia de usar el euro. Investigación económica, Barcelona, v. 71 , n. 281 , p. $59-82$, jul./set. 2012.

AISEN, Ari.; HAUNER, David. Budget deficits and interest rates: a fresh perspective. IMF Working Paper, v. 8, February 2008.

ALESINA, Alberto; ARDAGNA, Silvia. Tales of fiscal adjustment. Economic Policy, v. 13, n. 27, p. 489-585, 1998.

ARDAGNA, Silvia. Financial market's behavior around episodes of large chances in the fiscal stance. European Central Bank, September 2004. (Working Paper Series, n. 390).

ARDAGNA, Silvia; CASELLI, Francesco; LANE, Timothy. Fiscal discipline and the cost of public debt service: some estimates for OECD countries. European Central Bank, November 2004 (Working Paper Series, n. 411).

BALTAGI, Badi H. Econometric analysis of panel data. New York: John Wiley and Sons, 1995.

BARRO, Robert J. Output effects of government purchases. Journal of Political Economy, v. 89, n. 6, p. 1086-1121, 1981.

BARRO, Robert J.; REDLICK, Charles J. Macroeconomic effects from government purchases and taxes. NBER, September 2009 (Working Paper Series, n. 15369).

BARROS, Rodrigo W. F. Um estudo sobre o impacto da política fiscal na taxa de juros de curto prazo. Dissertação (Mestrado em Economia) - Escola de Economia de São Paulo, Fundação Getúlio Vargas, São Paulo, 2012.

BAXTER, Marianne; KING, Robert G. Fiscal policy in general equilibrium. The American Economic Review, v. 83, n. 3, p. 315-334, June 1993.

BLANCHARD, Oliver; PEROTTI, Roberto. An empirical characterization of the dynamic effects of changes in government spending and taxes on output. NBER, July 1999 (Working Paper Series, n. 7269).

BLINDER, Alan S.; SOLOW, Robert M. Does Fiscal Policy Matter? Econometric Research Program of Princeton University, n. 144, August 1972.

DORNBUSCH, Rudiger; FISCHER, Stanley. Macroeconomia. 5. ed. São Paulo: Pearson Makron Books, 1991.

ENGEN, Eric M.; HUBBARD, R. G. Federal Govermment Debt and Interest Rates. NBER Macroeconomics Annual 2004, v. 19, p. 83-160, April, 2005.

EVANS, Paul. Do large deficits produce high interest rates? The American Economic Review, v. 75, n. 1, March, 1985. 
FAVERO, Carlo A. Comments on fiscal and monetary policy interactions: empirical evidence on optimal policy using a structural new-Keynesian model. Journal of Macroeconomics, v. 26, p. 281-285, January, 2004.

GALE, William G.; ORSZAG, Peter R. Budget deficits, national saving, and interest rates. Brookings Institution and Tax Policy Center Working Paper, September, 2004.

GEMMELL, Norman; KNELLER, Richard; SANZ, Ismael. The timing and persistence of fiscal policy impacts on growth: evidence from OECD countries. The Economic Journal, v. 121, n. 550, p. F33-F58, February 2011.

GUJARATI, Damodar N.; PORTER, Dawn C. Econometria básica, 5. ed. Porto Alegre: AMGH Editora Ltda, 2011.

HEBOUS, Shafik. The Effects of discretionary fiscal policy on macroeconomic aggregates: A reappraisal. Munich Personal RePEc Archive, n. 23300, June 2010.

HEREDIA, Jourdy V. J. La crisis de deuda soberana de los PIGS de la zona Euro. Contribuiciones a la Economia, Febrero 2014.

IMF - INTERNATIONAL MONETARY FUND. International Finance Statistics (IFS). Disponível em: <https://www.bookstore.imf.org/authgatewaylogin?ssortn=http\%3a\%2f\%2felibrary-data.imf.org\%2fLoading.aspx\%3fLoadURL\%3d\%252fHandlers\%252fDownload.ashx\%253fid\%253d143114> Acesso em: 9 ago. 2014.

LAUBACH, Thomas. New evidence on the interest rate effects of budget deficits and debt. Journal of the European Economic Associaton, v. 7, n. 4, p. 858-885, Jun. 2009.

MOREIRA, Ajax; ROCHA, Katia. A política fiscal e as taxas de juros nos países emergentes. Economia Aplicada, v. 15, n. 3, p. 485-496, 2011.

PEROTTI, Robert. Estimating the effects of fiscal policy in OECD countries. Università Bocconi and Centre for Economic Policy Research, November 2004.

RAVN, Morten O.; UHLIG, Harald. On adjusting the Hodrick-Prescott filter for the frequency of observations. The Review of Economics and Statistics, v. 84, p. 371-380, May 2002.

ROMER, Christina D.; ROMER, David H. The macroeconomic effects of tax changes: estimates based on a new measure of fiscal shocks. NBER, Jul. 2007 (Working Papers Series, n. 13264).

SARGENT, Thomas J.; WALLACE, Neil. Some unpleasant monetarist arithmetic. Federal Reserve Bank of Minneapolis, v. 5, n. 3, 1981.

SIMS, Christopher A. Limits to inflation targeting. Department of Economics, Princeton University, May 2003.

TAYLOR, John B. Discretion versus policy rules in practice. Carnegie-Rochester Conference Series on Public Policy, v. 39, p. 195-214, 1993.

WDI - THE WORLD BANK. World Development Indicators. Disponível em: <http://databank. worldbank.org/data/views/variableselection/selectvariables.aspx?source=world-development-indicators >. Acesso em: 2 ago. 2014. 


\section{Apêndice}

Tabela 1 - Países selecionados na amostra com sua respectiva taxa de juros empregada

\begin{tabular}{|c|c|c|}
\hline & País & Taxa de juros \\
\hline 1 & Brasil & Taxa de juros dos títulos públicos \\
\hline 2 & Austrália & Taxa de juros no mercado monetário \\
\hline 3 & Bélgica & Taxa de juros dos títulos públicos \\
\hline 4 & Canadá & Taxa de juros dos títulos públicos \\
\hline 5 & República tcheca & Taxa de juros no mercado monetário \\
\hline 6 & Dinamarca & Taxa de juros no mercado monetário \\
\hline 7 & Estônia & Taxa de juros no mercado monetário \\
\hline 8 & Finlândia & Taxa de juros no mercado monetário \\
\hline 9 & França & Taxa de juros dos títulos públicos \\
\hline 10 & Alemanha & Taxa de juros no mercado monetário \\
\hline 11 & Grécia & Taxa de juros dos títulos públicos \\
\hline 12 & Islândia & Taxa de juros dos títulos públicos \\
\hline 13 & Irlanda & Taxa de juros no mercado monetário \\
\hline 14 & Israel & Taxa de juros dos títulos públicos \\
\hline 15 & Itália & Taxa de juros dos títulos públicos \\
\hline 16 & Cingapura & Taxa de juros no mercado monetário \\
\hline 17 & Espanha & Taxa de juros dos títulos públicos \\
\hline 18 & Suécia & Taxa de juros dos títulos públicos \\
\hline 19 & Reino unido & Taxa de juros dos títulos públicos \\
\hline 20 & Estados unidos & Taxa de juros dos títulos públicos \\
\hline 21 & Coréia & Taxa de juros no mercado monetário \\
\hline 22 & Peru & Taxa de juros no mercado monetário \\
\hline 23 & Hungria & Taxa de juros dos títulos públicos \\
\hline
\end{tabular}

